\title{
Sulpiride, a D2/D3 Blocker, Reduces Cataplexy but not REM Sleep in Canine Narcolepsy
}

\author{
Mutsumi Okura, M.D., Joyce Riehl, A.B., Emmanuel Mignot, M.D., Ph.D., and Seiji Nishino, M.D., Ph.D.
}

Cataplexy, an abnormal manifestation of REM sleep atonia, is currently treated with antidepressants. These medications also reduce physiological REM sleep and induce nocturnal sleep disturbances. Because a recent work on canine narcolepsy suggests that the mechanisms for triggering cataplexy are different from those for REM sleep, we hypothesized that compounds which act specifically on cataplexy, but not on REM sleep, could be developed. Canine studies also suggest that the dopamine D2/D3 receptor mechanism is specifically involved in the regulation of cataplexy, but little evidence suggests that this mechanism is important for REM sleep regulation. We therefore assessed the effects of sulpiride, a commonly used D2/D3 antagonist, on cataplexy and sleep in narcoleptic canines to explore the possible clinical application of D2/D3 antagonists for the treatment of human narcolepsy. Both acute and chronic oral administration of sulpiride (300 $\mathrm{mg} / \mathrm{dog}, 600 \mathrm{mg} / \mathrm{dog}$ ) significantly reduced cataplexy without noticeable side effects. Interestingly, the anticataplectic dose of sulpiride did not significantly reduce the amount of REM sleep. Sulpiride (and other D2/D3 antagonists) may therefore be an attractive new therapeutic indication in human narcolepsy. [Neuropsychopharmacology 23:528-538, 2000] (C) 2000 American College of

Neuropsychopharmacology. Published by Elsevier Science Inc.
KEY WORDS: Narcolepsy; Cataplexy; Sulpiride; Dopaminergic System; REM sleep

Narcolepsy is a neurological disorder characterized by excessive daytime sleepiness (EDS), fragmented nighttime sleep, cataplexy, hypnagogic hallucinations, and sleep paralysis (Aldrich 1992). EDS and cataplexy, "a sudden and bilateral loss of postural muscle tone in association with intense emotion" ICSD (International classification of sleep disorders ) (Diagnostic Classification Steering Committee, Thorpy MJ, Chairman 1990), are the most disabling symptoms of narcolepsy. EDS is usually treated using amphetamine-like stimulants (Al-

From the Center for Narcolepsy (MO, JR, EM, SN), Stanford Sleep Center, Stanford University School of Medicine, Palo Alto, CA; and Laboratory of Molecular Pharmacology (MO), Biosignal Research Center, Kobe University, Kobe, Japan.

Address correspondence to: Seiji Nishino, M.D., Ph.D., Center for Narcolepsy, Department of Psychiatry \& Behavioral Sciences, 1201 Welch Road, MSLS Building, Rm. P113, Palo Alto, CA 94304-5485. Tel.: 650-723-3724; Fax: 650-498-7761; E-mail: nishino@leland.stanford.edu

Received March 1, 2000; revised May 1, 2000; accepted May 4, 2000. drich 1992; Nishino and Mignot 1997). Although stimulants reduce daytime sleepiness, they have little effect on cataplexy, and thus additional anticataplectic medications are often needed in the treatment of narcolepsy. Tricyclic antidepressants have been the most commonly used anticataplectic agents since the 1960s (Akimoto et al. 1960; Aldrich 1992; Nishino and Mignot 1997). However, tricyclics have a variety of pharmacological effects, such as anticholinergic and antihistaminergic effects and/or alpha-1 adrenergic antagonism (Baldessarini 1983). Some of these effects are responsible for a variety of side effects during chronic treatment (dry mouth, tachycardia, weight gain, sexual dysfunction, sedation, and orthostatic hypotension) (Guilleminault 1994; Thorpy and Goswami 1990). Tricyclics also significantly affect nocturnal sleep by suppressing REM sleep, increasing muscle tone and inducing nocturnal movements (Guilleminault 1994). The long-term impact of chronically disturbing sleep in narcoleptic patients due to these compounds is unknown.

Canine narcolepsy is a naturally occurring animal model which presents behavioral, pharmacological and electrophysiological similarities to the human disorder 
(Baker and Dement 1985; Kaitin et al. 1986; Nishino and Mignot 1997). Narcoleptic dogs manifest a short sleep latency, fragmented sleep patterns, and cataplexy (Kaitin et al. 1986; Nishino et al. 1999). It was recently discovered that mutations in the gene encoding a receptor for hypocretins (also called orexins) induces genetic narcolepsy in Dobermans and Labradors (Lin et al. 1999). Subsequently, it was also found that cerebrospinal fluid hypocretin-1 levels are low in human narcoleptic subjects, indicating that a deficit in hypocretin neurotransmission is also involved in human narcolepsy (Nishino et al. 2000b). Thus, the use of the canine model to uncover the pathophysiology of narcolepsy and to develop new treatments for human narcolepsy is further warranted.

Previous pharmacological studies in canine narcolepsy have demonstrated that decreased monoaminergic transmission is one of the most important factors in the pathophysiology of narcolepsy (Mignot et al. 1989; Nishino et al. 1990; Nishino and Mignot 1997; Reid et al. 1998). Inactivation of catecholaminergic transmission aggravates cataplexy and/or induces sleep in these animals [see (Nishino and Mignot 1997)]. We further identified several catecholaminergic receptor subtypes specifically involved in the regulation of cataplexy, namely adrenergic postsynaptic $\alpha-1 b$, presynaptic $\alpha-2$ and dopaminergic D2-type receptors (Mignot et al. 1989; Nishino et al. 1991, 1993b, 1995). These results are also compatible with the recent discoveries of a deficit in hypocretin neurotransmission in narcolepsy (Chemelli et al. 1999; Lin et al. 1999; Nishino et al. 2000b) since hypocretin neurons project intensively to monoaminergic cell groups and are excitatory in nature (de Lecea et al. 1998; Hagan et al. 1999; Peyron et al. 1998).

Because narcoleptic patients often exhibit sleep onset REM periods (SOREMPs), it is believed that REM sleep can intrude in active wake or sleep onset, resulting in cataplexy, sleep paralysis and hypnagogic hallucinations (Roth et al. 1969; Takahashi 1971). Thus, abnormal generation of REM sleep might be central to narcolepsy. However, a recent study of REM sleep cyclicity in dogs revealed that a clear 30-min cyclicity exists in both narcoleptic and control animals (Nishino et al. 1999). In contrast to REM sleep, cataplexy can be elicited anytime upon emotional stimulation, and no 30-min cyclicity is observed (Nishino et al. 1999). Based on these results, we hypothesize that specific mechanisms for triggering cataplexy, but not REM sleep, may exist, and that pharmacological treatments that specifically target this abnormal manifestation (i.e., with no effect on physiological sleep) could be developed.

Dopaminergic D2/D3 agonists administrated systemically or perfused locally into the midbrain dopaminergic nuclei [i.e., ventral tegmental area (VTA) and substantia nigra (SN) or diencephalic dopaminergic nuclei] significantly enhance cataplexy, while D2/D3 antagonists sig- nificantly reduce it in the canine model (Honda et al. 1999; Okura et al. 1999; Reid et al. 1996). It is known that D2/D3 autoreceptors are enriched in the SN and the VTA and that systemic or local administration of D2/D3 agonists into these structures significantly reduces the firing rate of dopaminergic neurons (Miller et al. 1983; Piercey et al. 1996; Trulson 1985). Thus, changes in the activity of dopaminergic neurons in the midbrain may be critical for the regulation of cataplexy (Nishino et al. 2000a). This result, however, contrasts with the well-documented lack of evidence of a role for midbrain dopaminergic systems in the regulation of REM sleep (Miller et al. 1983; Trulson 1985). D2/D3 receptor-mediated dopaminergic activity in the midbrain and diencephalon may thus be more specifically involved in the regulation of cataplexy than in REM sleep.

In this study, we therefore evaluated and characterized the effects on canine narcolepsy of acute and chronic administration of sulpiride, one of the most common clinically used D2/D3 antagonists, aiming at a possible clinical application of D2/D3 antagonists for human narcolepsy.

\section{MATERIALS AND METHODS}

\section{Animals}

Six genetically narcoleptic Doberman pinschers (mean age \pm S.D., $1.8 \pm 1.0$ years; and mean weight \pm SD, $27.5 \pm$ $4.2 \mathrm{~kg}$; three females and three males) were included in this study for cataplexy testing. A total of four narcoleptic Dobermans (four males; $2.9 \pm 1.3$ years) chronically implanted with electroencephalogram (EEG), electrooculogram (EOG), and electromyogram (EMG) electrodes, were used for polygraphic recordings. Dogs were housed at the Stanford University Department of Comparative Medicine in individual stainless steel cages $\left(100 \times 180 \mathrm{~cm}^{2}\right)$. All experiments were carried out in strict accordance with the guidelines described in the National Institutes of Health Guide for the Care and Use of Laboratory Animals.

\section{Food-Elicited Cataplexy Test}

The Food-Elicited Cataplexy Test (FECT) is a standardized biological assay used to assess the severity of cataplexy (Baker and Dement 1985; Nishino and Mignot 1997). During the FECT, one animal is brought to an experimental room where 12 pieces of wet dog food are placed in sequence on the floor (Baker and Dement 1985; Nishino and Mignot 1997). Because food is an emotionally exciting stimulus for dogs, affected animals experience multiple cataplectic attacks during the test. The experimenter notes the number and duration of any cataplectic attacks as the dog consumes each piece of food in succession. FECTs are always administered in duplicate. The total 
time spent in cataplexy (TSC), which is the sum of the duration of each of the cataplectic episodes, and the number of cataplectic attacks were used as the dependent variables for the analyses.

\section{EEG Recording}

Polygraphic sleep recordings were performed on a total of four implanted dogs to assess the effects of acute and chronic oral administration of sulpiride, and three of the four dogs were used in each session. EEG, EMG and EOG electrodes were implanted with the assistance of a Kopf stereotaxic frame (David Kopf Instruments, Tujunga, CA) and a reference canine brain atlas (Lim et al. 1960). Electrodes for EEG recording were secured to the skull over the mid-frontal, lateral-parietal and occipital cortices, and those for EOG recording were secured into the orbit of the frontal bone. Stainless steel wires were inserted into dorsal neck muscles for recording EMG. The surgical procedure was previously described in detail in Nishino et al. (1995).

Dogs were freely-moving in a recording room $(3 \times 3$ $\mathrm{m})$ with lights on for $6 \mathrm{~h}$ and were observed from an adjoining room with a video camera. Thirty-second epochs were visually scored using previously described criteria that are based on the frequency and amplitude patterns of two cortical tracings (fronto-parietal and fronto-occipital), EMG and EOG (Nishino et al. 1995). The amount of time spent in each sleep stage (wake, drowsy, light sleep, deep sleep, REM sleep, and cataplexy) during the 6-h period was calculated.

Data (mean \% \pm S.E. of each sleep stage and its range) previously obtained under the same recording conditions and with the same scoring criteria in 10 narcoleptic and 6 control dogs are as follows; wake $46.7 \pm 5.7$ (20.3-73.7) vs. $52.3 \pm 5.4(38.5-69.2) \%$, drowsy $13.0 \pm$ 1.3 (7.3-18.6) vs. $12.4 \pm 1.3(7.2-15.2) \%$, light sleep $15.0 \pm 2.8(4.7-31.4)$ vs. $16.2 \pm 2.5(9.7-28.0) \%$, deep sleep $14.3 \pm 3.6(1.5-40.5)$ vs. $15.7 \pm 2.8(7.1-24.8) \%$, REM sleep $6.6 \pm 1.7(0.6-13.3)$ vs. $4.4 \pm 1.3(1.2-9.8) \%$, and cataplexy $3.1 \pm 0.8(0.69-8.43) \%$ in narcoleptic dogs.

\section{Experimental Designs}

Acute Effects of Sulpiride on Cataplexy and Daytime Sleep. Six narcoleptic dogs were used to determine the time course of action of acute administration of sulpiride [( \pm )-Sulpiride RBI, Natick, MA] on cataplexy using three different doses $(150,300,600 \mathrm{mg} / \mathrm{dog}$, p.o.). FECTs were performed $2 \mathrm{~h}$ prior to oral drug administration, immediately proceeding drug administration and $2,4,6,8,24$, and $48 \mathrm{~h}$ after drug administration.

Polygraphic sleep recordings were run for a duration of $6 \mathrm{~h}$, beginning $2 \mathrm{~h}$ after drug administration (0900 to 1500) on three implanted dogs to assess the effects of acute oral administration of sulpiride on sleep and wakefulness. Two recording sessions were conducted for each animal. Each recording session consisted of three recordings: baseline, low dose ( $300 \mathrm{mg} / \mathrm{dog}$, p.o.), and high dose $(600 \mathrm{mg} / \mathrm{dog}$, p.o.). The half-life of sulpiride (100-400 mg p.o.) is reported to be $6.3-8.4 \mathrm{~h}$ (Wagstaff et al. 1994), and each recording was repeated at 48-h interval. Furthermore, the order of the recordings for baseline, low and high doses was randomized.

Coadministration of Sulpiride and D3 Agonists. Low doses of dopaminergic (D2/D3) agonists aggravate cataplexy, and the effect on cataplexy of these compounds is likely to be mediated by stimulation of D2/ D3 autoreceptors (Nishino et al. 1991; Reid et al. 1996). In order to demonstrate that the anticataplectic effect of sulpiride is mediated by D2/D3 autoreceptor blockade, we assessed the effects of sulpiride on selective D2/D3 agonist-induced cataplexy. After baseline FECTs, sulpiride $(300 \mathrm{mg} / \mathrm{dog}$ or $600 \mathrm{mg} / \mathrm{dog}$ p.o. with $3 \mathrm{~g}$ of wet $\operatorname{dog}$ food) or placebo ( $3 \mathrm{~g}$ of wet dog food) was orally administered, and FECTs were again carried out $6 \mathrm{~h}$ later. At the 6-h point, immediately following the second FECT, either quinpirole $(6 \mu \mathrm{g} / \mathrm{kg})$ or $7-\mathrm{OH}-$ DPAT $(6 \mu \mathrm{g} / \mathrm{kg})$, was injected, and FECTs were repeated 5 min later.

Chronic Effects of Sulpiride on Cataplexy and Daytime Sleep. The long-term effects of sulpiride were also evaluated. Baseline FECTs were conducted on days -6 , -4 , and -2 prior to the beginning of chronic drug administration. Sulpiride was given orally on a daily basis for 14 consecutive days (days 0-13). FECTs were performed $6 \mathrm{~h}$ after drug administration. A beginning dose of $300 \mathrm{mg} / \mathrm{dog}$ per day was administered. When the reduction in TSC for an animal was less than $25 \%$ of the mean TSC at baseline for 2 consecutive days, the dose of sulpiride was increased by $100 \mathrm{mg}$ (highest dose allowed: $600 \mathrm{mg} / \mathrm{dog}$ per day). FECTs were also performed on days 14, 15, 16, 19 and 21 after cessation of drug administration to monitor any withdrawal effects. Blood pressure (BP), heart rate (HR), rectal temperature (RT), and weight were also measured to monitor side effects. Blood samples were collected once a week to monitor SGOT, SGPT, alkaline phosphatase, BUN, creatinine, CPK levels, and hematology (blood cell counts and morphology).

The effect of chronic oral administration of sulpiride on sleep was monitored by polygraphic recordings in three implanted animals. Sulpiride (300 mg) was given orally for 14 consecutive days (days 0-13) and polygraphic recordings were performed on days $-5,-3,-1$ (baseline), 5, 6, 7 (first week), and 11, 12, 13 (second week).

\section{Data Analysis}

Friedman's non-parametric analysis of variance (ANOVA) was used to test the significance of the over- 
all effects observed in cataplexy $(n=6)$ and sleep recording tests after both acute ( 3 animals, 2 session each, a total of 6 sessions) and chronic administration ( 3 animals, recordings on each animal include 3 baseline, 3 first week, and 3 second week sessions). Due to a limitation in the number of implanted animals available for sleep recordings, multiple sessions in the same animals were handled as independent data. If the overall effects were significant $(p<.05)$, a non-parametric post-hoc test (Steel) was applied to test the significance between each testing point and baseline. For analyzing the effect of drug coadministration, a repeated measures ANOVA was used to assess dose effects, trial (D2/D3 antagonist and agonist) effects, and their interaction. A post-hoc analysis (Tukey) was applied to assess the dose effects against the placebo session.

\section{RESULTS}

\section{Effects of Acutely-administered Sulpiride on Cataplexy and Daytime Sleep}

Oral administration of sulpiride (300, $600 \mathrm{mg} / \mathrm{dog}$, p.o.) significantly reduces cataplexy both in the TSC and the number of cataplectic attacks (Figure 1). Onset of anticataplectic effect began 2-4 h after administration, and lasted for over $24 \mathrm{~h}$ (maximal effect at 6-8 hours) after drug administration. The anticataplectic effect of sulpiride was dose-dependent, and cataplexy was completely suppressed by the administration of $600 \mathrm{mg}$ in most animals $(5 / 6$ dogs $)$.

In contrast, a single dose of sulpiride $(300 \mathrm{mg}$ and $600 \mathrm{mg}$, p.o.) did not significantly modify the amount of time spent in wake or any sleep stage in narcoleptic animals (Figure 2, Table 1). It should also be emphasized that the amount of REM sleep was not significantly reduced, changing from $4.65 \%$ to $3.26 \%$ ( $p=.11$, Friedman's nonparametric ANOVA) during the entire $6 \mathrm{~h}$ of recording (2-8 hours after the administration of $600 \mathrm{mg}$ of sulpiride) (Table 1). No significant effect on any sleep parameters was observed even when the polygraphic data were analyzed in separate 2-h bins (2-4, 4-6, 6-8 h after drug administration). REM sleep was only reduced from $5.97 \%$ to $4.65 \%$ ( $p=.51$ ) $6-8 \mathrm{~h}$ after administration of $600 \mathrm{mg}$ of sulpiride, the period where a maximal reduction in cataplexy was observed. Acute administration of sulpiride thus has a differential effect on cataplexy and REM sleep.

We have previously demonstrated that the sleep/ wake pattern of narcoleptic dogs is significantly fragmented compared to control dogs (Kaitin et al. 1986; Mitler and Dement 1977; Nishino et al. 1999). Narcoleptic dogs exhibit a higher frequency of episodes (episodes/h) of wake, drowsy, light sleep and deep sleep, and the mean duration of each episode (min/episode) is significantly shorter, although the total amount of sleep does not differ between narcoleptic and control dogs (Kaitin et al. 1986; Mitler and Dement 1977; Nishino et al. 1999). In the current study, we found that (a)

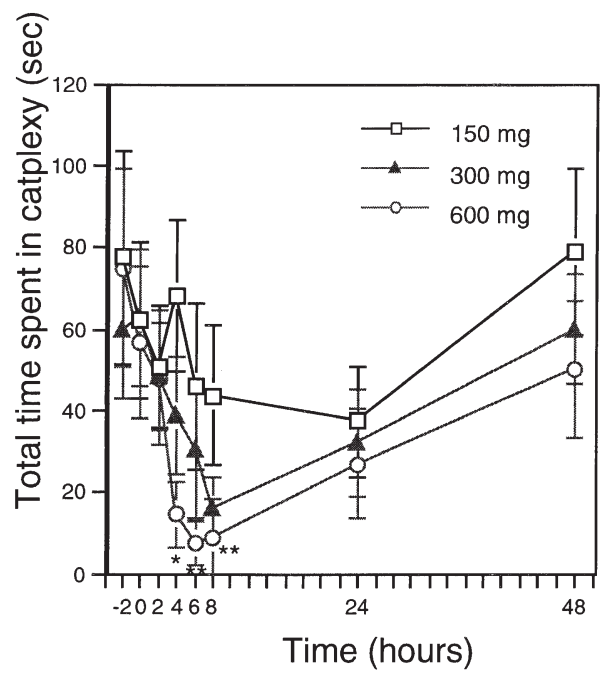

(b)

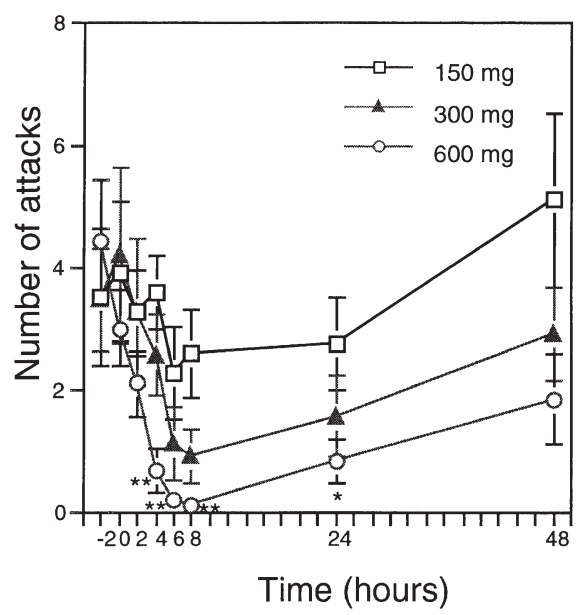

Figure 1. Effects of acute oral administration of sulpiride. Each point represents the mean value with S.E. of (a) the total time spent in cataplexy (TSC) and (b) the number of cataplectic attacks (NA) of six animals. The duration and number of cataplectic attacks were reduced by oral administration of $300 \mathrm{mg}$ and $600 \mathrm{mg}$ of sulpiride $(150 \mathrm{mg}, p=.084$ for TSC, $p=$ .177 for NA; $300 \mathrm{mg}, p=.003$ for TSC, $p=.006$ for NA; $600 \mathrm{mg}, p<.001$, Friedman ANOVA). Effects on cataplexy first appeared 2-4 h after drug administration and persisted for over $24 \mathrm{~h}$. Statistical significance, compared to each baseline (time 0$)$, is indicated by asterisks ${ }^{* *} p<.01,{ }^{*} p<.05$, Steel-post hoc test). 


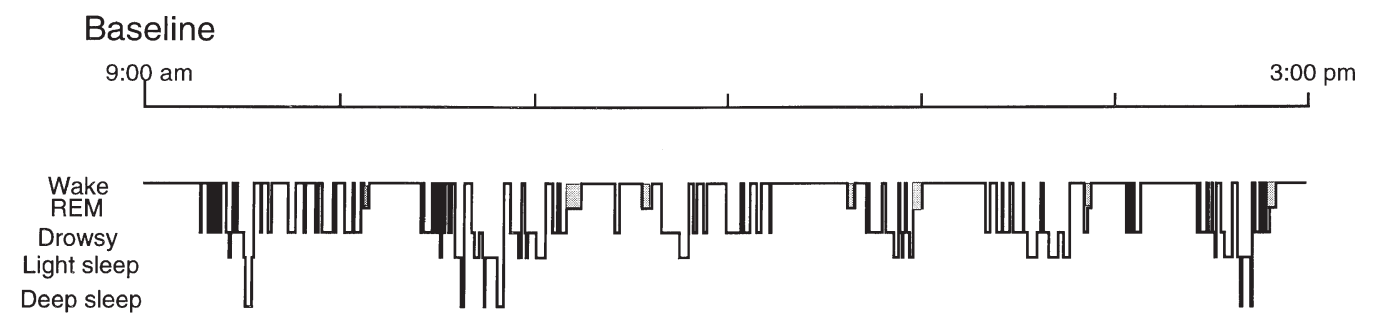

300 mg p.o.
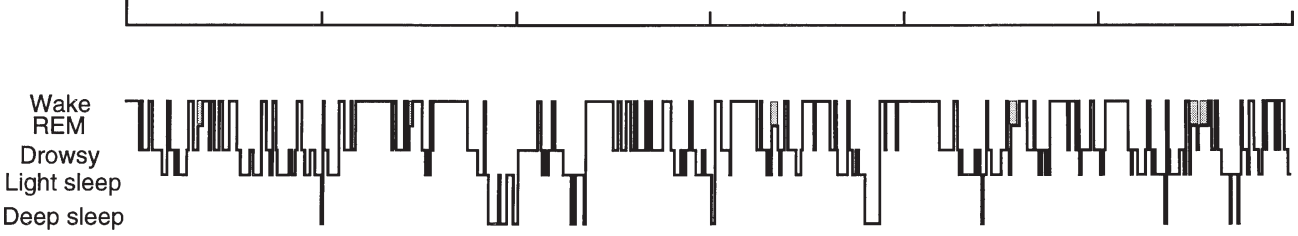

$600 \mathrm{mg}$ p.o.

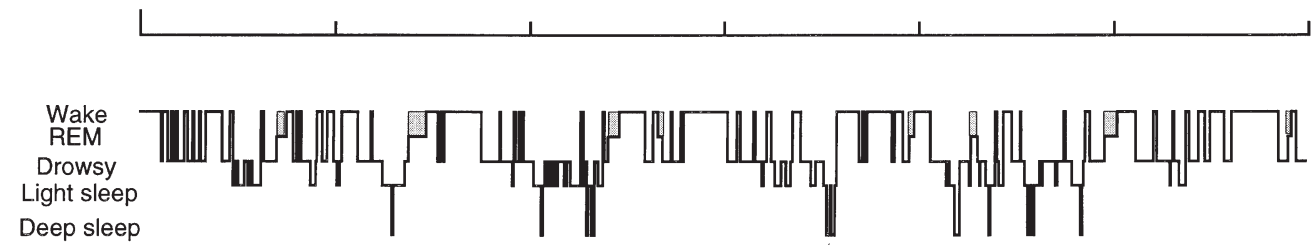

Figure 2. Hypnograms during acute oral administration of sulpiride. Typical hypnograms demonstrating acute effects of sulpiride on vigilance states in a representative animal are shown. The top hypnogram represents baseline. The middle and bottom hypnograms represent low $(300 \mathrm{mg})$ and high $(600 \mathrm{mg})$ doses of administration of sulpiride, respectively. Drugs were administrated $2 \mathrm{~h}$ prior to recordings. Anticataplectic doses of sulpiride (300 $\mathrm{mg}$ or $600 \mathrm{mg}$ ) did not reduce REM sleep (see also Figure 1 and Table 1).

acute sulpiride administration did not improve sleep fragmentation; no changes in the mean frequency of episodes or the mean duration of episodes of any vigilance state were observed (data not shown).

\section{Coadministration of D3 Agonists and Sulpiride}

As previously reported (Nishino et al. 1998b), low doses of the D2/D3 agonists quinpirole $(6 \mu \mathrm{g} / \mathrm{kg}$, i.v. $)$ and 7-OHDPAT $(6 \mu \mathrm{g} / \mathrm{kg}$, i.v.) significantly aggravated canine cata- plexy (Figure 3). The administration of these compounds at these doses also induced short-lasting emesis and behavioral sedation in narcoleptic dogs [see also (Nishino et al. 1991)]. When narcoleptic animals were pretreated with sulpiride (300 mg, $600 \mathrm{mg}$ p.o.), the cataplexy-aggravating effects of quinpirole and 7-OH-DPAT were blocked (Figure 3). The antagonism by sulpiride was dose-dependent, and the pre-administration of $600 \mathrm{mg}$ of sulpiride completely blocked the cataplexy-enhancing effects of D2/D3 agonists. Furthermore, none of the animals pre-treated

Table 1. Effect of Acute Oral Administration of Sulpiride on Vigilance States in Narcoleptic Dobermans

\begin{tabular}{|c|c|c|c|c|}
\hline Vigilance State & Baseline & 300 mg, p.o. & $600 \mathrm{mg}$, p.o & $p$-Value \\
\hline Cataplexy & $0.12 \% \pm 0.12$ & $0.00 \% \pm 0.00$ & $0.00 \% \pm 0.00$ & .88 \\
\hline Wake & $48.43 \% \pm 3.59$ & $46.27 \% \pm 2.52$ & $44.51 \% \pm 2.11$ & .51 \\
\hline REM & $4.65 \% \pm 0.89$ & $3.06 \% \pm 0.71$ & $3.26 \% \pm 0.62$ & .11 \\
\hline Drowsy & $22.08 \% \pm 1.84$ & $23.13 \% \pm 2.52$ & $26.57 \% \pm 3.82$ & .31 \\
\hline Light Sleep & $22.48 \% \pm 3.74$ & $24.79 \% \pm 1.75$ & $23.33 \% \pm 2.61$ & .75 \\
\hline Deep Sleep & $2.25 \% \pm 0.28$ & $2.75 \% \pm 0.60$ & $2.31 \% \pm 0.24$ & 1.00 \\
\hline
\end{tabular}

Sulpiride was orally administered daily at 7:00 A.M. to three narcoleptic Dobermans. Polygraphic recordings were conducted for $6 \mathrm{~h}$ from 9:00 A.M. to 3:00 P.M. Three recordings [baseline, low dose $(300 \mathrm{mg})$, and high dose $(600 \mathrm{mg})$ ] were carried out twice in each animal. Sulpiride had no effect on any sleep stage during 6-h daytime polygraphic recordings. Because cataplexy was only observed in one out of six baseline sessions, reduction in cataplexy during the sulpiride sessions did not reach a statistically significant level. 
(a)

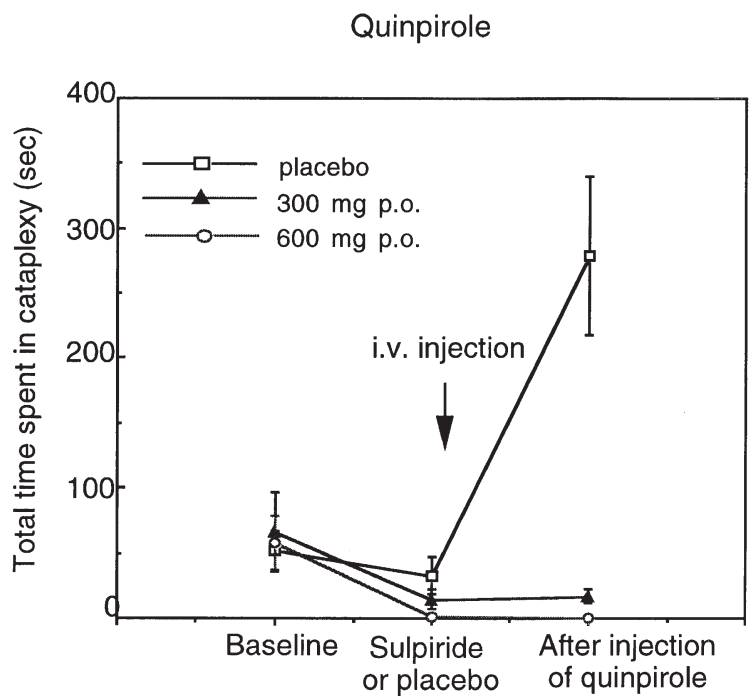

(b)

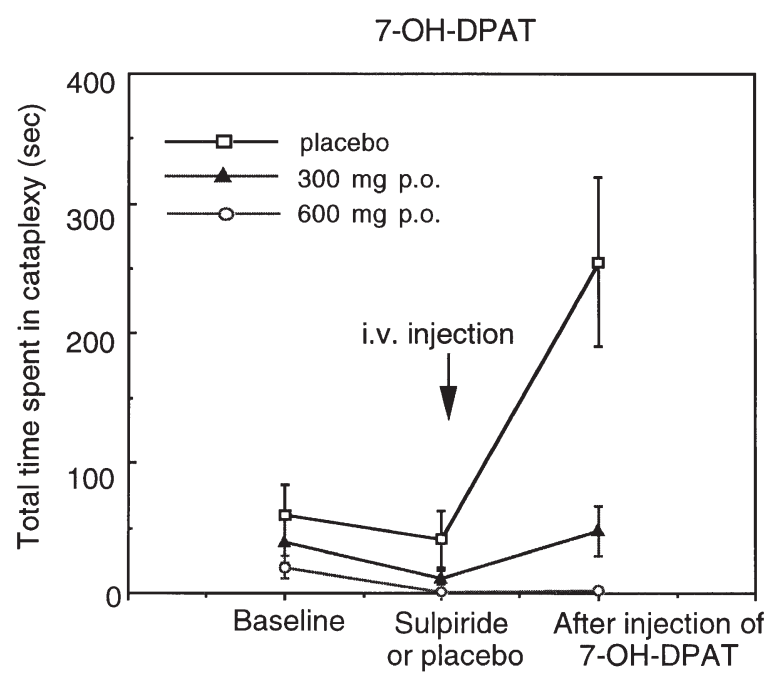

Figure 3. Effects of sulpiride on dopaminergic (D2/D3) agonist-induced cataplexy. Baseline TSC was assessed by FECT at 9:00 A.M. After baseline FECTs, sulpiride (300 mg p.o. and $600 \mathrm{mg}$ p.o.) or placebo was orally administered, and FECTs were repeated $6 \mathrm{~h}$ later. Following the second FECT, a D2/D3 agonist (either $6 \mu \mathrm{g} / \mathrm{kg}$ quinpirole or $6 \mu \mathrm{g} / \mathrm{kg}$ 7-OH-DPAT) was immediately injected, and FECTs were again performed 5 min after drug administration. Each point represents the mean TSC with SE of six animals. (a) Sulpiride treatments (300 mg and $600 \mathrm{mg}$ p.o.) reduce cataplexy and block the cataplexy aggravating effects of quinpirole. Analysis using the repeated measures ANOVA revealed dose-dependent differences $(p=$ .0016) in TSC, as well as differences among different trials (baseline, sulpiride and quinpirole sessions) $(p=.0015)$. The interaction between the dose effect and the trials was highly significant $(p<.0001)$. A post-hoc Tukey analysis further indicates that effects during both the $300 \mathrm{mg}(p<.01)$ and $600 \mathrm{mg}(p<.01)$ sessions differ from the placebo session. (b) Sulpiride treatments (300 mg and $600 \mathrm{mg}$ p.o.) reduce cataplexy and block the cataplexy-aggravating effects of 7-OH-DPAT. Analysis using the repeated measures ANOVA revealed dose-dependent differences in TSC (placebo, $300 \mathrm{mg}$ and $600 \mathrm{mg})(p=.001)$, differences among different trials (baseline, sulpiride and quinpirole sessions) ( $p=.0015)$, as well as difference in the interaction between the dose effect and the trials $(p<.0001)$. A post-hoc Tukey analysis further indicates that effects of both the $300 \mathrm{mg}(p<.01)$ and $600 \mathrm{mg}(p<.01)$ session significantly differ from the placebo session.

with sulpiride vomited or showed behavioral sedation after injections of D2/D3 agonists.

\section{Effects of Chronically Administered Sulpiride on Cataplexy and Daytime Sleep}

Narcolepsy is a chronic disorder, and chronic pharmacological treatment is typically required. The effect of 2-week chronic administration of sulpiride was thus evaluated in canine narcolepsy with systematic side effect monitoring, in order to further explore the possible clinical application of D2/D3 antagonists for the treatment of human cataplexy. Results of the chronic study indicate that sulpiride (starting dose, $300 \mathrm{mg}$, p.o.) significantly reduced cataplexy (Figure 4). In two animals, the anticataplectic efficacy was reduced during the 2-week drug administration, prompting us to increase the dose for these animals (final doses: 400 and $500 \mathrm{mg}$, respectively). With this dose adjustment, cataplexy was successfully managed in all animals throughout the trial period. Number of cataplectic attacks were also reduced, in parallel with
TSC (data not shown). Comparison of the averaged durations of cataplectic attacks for six animals revealed a significant reduction of cataplexy during weeks 1 and 2 of drug administration when compared to baseline, while no statistical difference was observed between weeks 1 and 2. Thus, drug tolerance to the anticataplectic effect was partial. Upon withdrawal of the compound, the reduction of cataplexy persisted for 2 more days, followed by a subsequent increase in severity of cataplexy (175\% TSC at day 22 compared to mean baseline TSC) before returning to baseline. No significant changes in $\mathrm{HR}, \mathrm{BP}$, and RT were observed during baseline, drug and withdrawal weeks. No noticeable behavioral changes were observed. Only one female animal had a transient reduction in food consumption during days 610 and a transient loss in body weight $(-2 \mathrm{~kg} ; 7 \%$ decrease). There were no changes in the blood chemistry and hematology tests (see Methods) in any of the animals. Significant reduction of cataplexy was observed in both females $(n=3)$ and males $(n=3)$. None of the dogs had galactorrhea. 


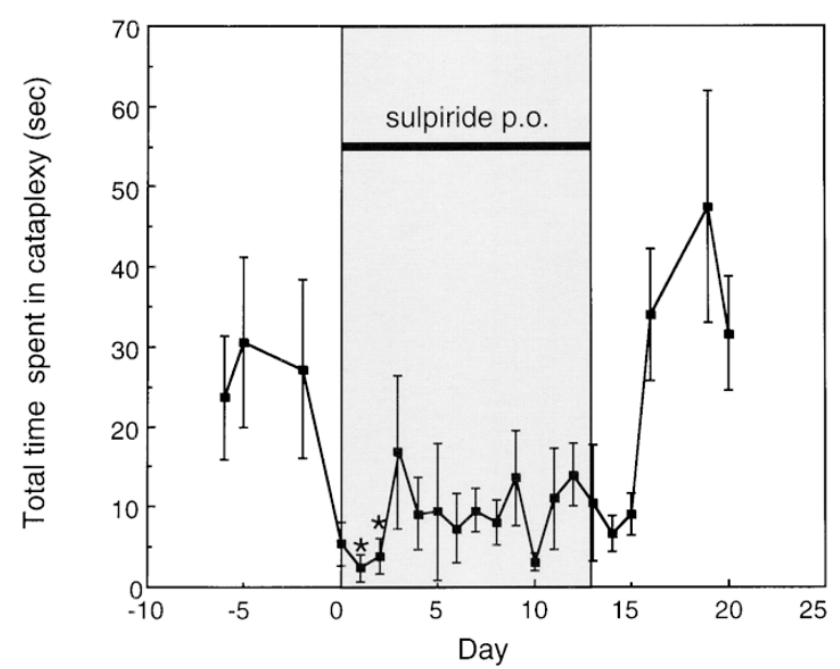

Figure 4. Effects of chronic oral sulpiride administration on cataplexy. Sulpiride (starting dose: $300 \mathrm{mg} / \mathrm{dog}$ ) was orally administered at 8:30 A.M. from day 0 to day 13. FECTs were carried out daily at 2:30 P.M. The dosage was increased by $100 \mathrm{mg}$ for each individual animal when the reduction in TSC for 2 consecutive days was less than $25 \%$ compared to the mean baseline TSC. An increase in dosage was necessary for two animals; one animal's dose was increased to $400 \mathrm{mg}$ on day 9 and again increased to $500 \mathrm{mg}$ on day 13, while another animal required an increase to $400 \mathrm{mg}$ on day 13 . The duration of the cataplectic attacks was reduced for the overall 2-week period $(p<.001$, Friedman ANOVA). The time points in which TSC was significantly smaller than the baseline are indicated with asterisks $\left({ }^{*} p<.05\right.$, Steel-post hoc test). The average duration of cataplectic attacks for each dog during baseline, week 1 , week 2 and withdrawal also differed $(p<.001$, Friedman ANOVA). Posthoc tests revealed a significant reduction in cataplexy during week 1 and week 2 compared to the baseline.

In a separate session, we additionally investigated the effect of chronic oral administration of sulpiride $(300 \mathrm{mg})$ on daytime sleep in three implanted narcoleptic animals. Results showed that chronic administration of sulpiride reduced wake and increased light and deep sleep (Table 2). However, consistent with the results obtained after acute administration, sulpiride did not reduce REM sleep significantly during either the entire 6-h recording session or for a period of 6-8 $\mathrm{h}$ after drug administration (Table 2). In contrast to the acute drug session, however, the mean duration of drowsy, light sleep and deep sleep became longer during drug sessions, and the effects on light and deep sleep were statistically significant (Table 2). Thus, chronic administration of sulpiride tended to improve sleep fragmentation in narcoleptic dogs.

\section{DISCUSSION}

Cataplexy, one of the most disabling symptoms of narcolepsy, is often regarded as a dissociated manifesta- tion of REM sleep: one of the components of REM sleep, inhibition of muscle tone, suddenly occurs during active wake. In agreement with this interpretation, a significant overlap in electrophysiological findings between cataplexy and REM sleep has been reported (Siegel et al. 1991; Wu et al. 1999). H-reflex activity, a muscle response with monosynaptic latency due to excitation of some Ia afferents in the spinal cord, profoundly diminishes or disappears during both REM sleep and cataplexy (Guilleminault et al. 1974). These results suggest that the motor inhibitory components of REM sleep at the level of the lower brainstem and the spinal cord are also involved in cataplexy. Other experiments, however, suggest differences between cataplexy and REM sleep. Cataplexy is most typically triggered by emotional excitation. Phasic phenomena of REM sleep, such as rapid eye movements and muscle twitching, are sometimes, but not always, observed during cataplexy (Nishino et al. 1999; Siegel et al. 1992). Although narcoleptic dogs also exhibit SOREMPs, there is little evidence to suggest that the generation of REM sleep itself is altered in narcoleptic dogs (Nishino et al. 1999). There is no significant difference in the amount of REM sleep between narcoleptic and control dogs during the daytime or nighttime (Kaitin et al. 1986; Nishino et al. 1999). Furthermore, a recent analysis of the cyclicity of REM sleep and cataplexy in narcoleptic canines demonstrated that a normal 30-min ultradian rhythm of occurrence of REM sleep is observed in narcoleptic animals (Nishino et al. 1999). In contrast to REM sleep, cataplexy can be elicited anytime upon emotional stimulation, and no 30-min cyclicity is observed (Nishino et al. 1999). SOREMPs in narcoleptic dogs may therefore be mainly due to a disturbance in sleep state maintenance, rather than an abnormality in REM sleep generation (Nishino et al. 1999). These results suggest that the mechanisms for triggering cataplexy are different from those for generating REM sleep (Nishino et al. 1999), even if both phenomena share a common executive system (Guilleminault et al. 1974). It may therefore be possible to develop more specific pharmacological treatments for cataplexy that have little effect on physiological REM sleep.

Tricyclic antidepressants are the most commonly used anticataplectic agents in humans. These compounds enhance central monoaminergic transmission by presynaptic inhibition of monoamine reuptake (Baldessarini 1983). However, most compounds lack selectivity for each monoamine (i.e., NE, DA and 5HT), and their modes of action on cataplexy have been debated (Schrader et al. 1986). Recent pharmacological experiments using the canine narcolepsy model and newer selective monoamine uptake inhibitors have demonstrated that the NE uptake mechanism is one of the most important mechanisms mediating the anticataplectic effect of tricyclics; all selective NE uptake inhibi- 
Table 2. Effect of Chronic Oral Administration of Sulpiride on Vigilance States in Narcoleptic Dobermans

\begin{tabular}{|c|c|c|c|c|}
\hline Vigilance state & Baseline & First week & Second week & $p$-Value \\
\hline \multicolumn{5}{|c|}{ Percentage of each vigilance state } \\
\hline Cataplexy & $0.39 \% \pm 0.13$ & $0.22 \% \pm 0.10$ & $0.17 \% \pm 0.09$ & .17 \\
\hline Wake & $53.63 \% \pm 1.81$ & $39.10 \% \pm 3.22^{* *}$ & $39.14 \% \pm 2.92^{*}$ & $<.01$ \\
\hline REM & $3.35 \% \pm 0.71$ & $3.95 \% \pm 0.53$ & $3.18 \% \pm 0.49$ & .12 \\
\hline Drowsy & $20.51 \% \pm 2.64$ & $24.88 \% \pm 4.27$ & $26.45 \% \pm 4.53$ & .37 \\
\hline Light sleep & $19.34 \% \pm 2.05$ & $24.51 \% \pm 2.60^{* *}$ & $23.97 \% \pm 2.72 *$ & $<.01$ \\
\hline Deep sleep & $2.79 \% \pm 0.78$ & $7.35 \% \pm 1.81^{* *}$ & $7.10 \% \pm 2.34$ & $<.01$ \\
\hline \multicolumn{5}{|c|}{ Mean duration of each episode (minutes/episodes) } \\
\hline Cataplexy & $2.67 \pm 0.42$ & $2.17 \pm 0.53$ & $3.29 \pm 1.1$ & .76 \\
\hline Wake & $5.66 \pm 0.46$ & $5.35 \pm 0.76$ & $5.13 \pm 0.54$ & .12 \\
\hline REM & $5.04 \pm 0.86$ & $5.34 \pm 0.61$ & $4.70 \pm 0.53$ & .34 \\
\hline Drowsy & $2.27 \pm 0.19$ & $3.20 \pm 0.43$ & $3.39 \pm 0.45$ & .04 \\
\hline Light sleep & $3.55 \pm 0.11$ & $4.40 \pm 0.29^{*}$ & $5.01 \pm 0.46^{*}$ & .03 \\
\hline Deep sleep & $2.49 \pm 0.29$ & $3.86 \pm 0.77^{*}$ & $4.40 \pm 0.64^{* *}$ & .01 \\
\hline
\end{tabular}

( $p$-value by Friedman ANOVA, ${ }^{* *} ; p<.01, * ; p<.05$ by Steel post-hoc test)

Three animals were given $300 \mathrm{mg}$ sulpiride orally for 14 days at 8:00 A.M. Six-h baseline EEG recordings (10:00 A.M.-4:00 P.M.) were conducted on days $-5,-3,-1$. Recordings during the first week of drug administration were performed on days 4, 5, 6 and, on days $11,12,13$ during the second week. Although wake was significantly decreased and light sleep was significantly increased by chronic sulpiride administration, the amount of REM sleep was not significantly affected.

Chronic administration of sulpiride-improved sleep fragmentation. There was a significant tendency towards longer mean duration of drowsy, light sleep, and deep sleep.

tors potently reduce cataplexy, while selective $5 \mathrm{HT}$ and DA uptake inhibitors have little or no effect (Mignot et al. 1993; Nishino et al. 1993a). In contrast, the DA uptake mechanism is found to be important for the control of EEG arousal; selective DA uptake inhibitors and modafinil potently induce EEG arousal, and their in vivo potency on EEG arousal correlates well with their in vitro binding affinity to the dopamine transporter (Nishino et al. 1998a). Canine experiments have further identified several monoamine receptor subtypes that are specifically involved in the regulation of cataplexy, namely adrenergic postsynaptic $\alpha-1 b$ (Mignot et al. 1989), presynaptic $\alpha-2$ (Nishino et al. 1993b) and dopaminergic D2/D3 receptors (Nishino et al. 1991). Furthermore, the acting sites of D2/D3 compounds have also been identified recently; D2/D3 agonists perfused into the VTA, SN and diencephalic dopamine cell groups, such as A11, significantly aggravate cataplexy, while D2/D3 antagonists significantly reduce cataplexy (Honda et al. 1999; Okura et al. 1999; Reid et al. 1996). It is known that systemically or locally applied D2/D3 agonists into the VTA or SN significantly reduce the firing rate of mesencephalic DA neurons (Piercey et al. 1996; Trulson 1985), while DA uptake inhibitors have no effect on the firing of mesencephalic DA neurons (Nissbrandt et al. 1991). In contrast, the DA uptake mechanism is known to have physiological and pharmacological importance in the mesolimbocortical and mesostriatal projections (Nissbrandt et al. 1991). Thus, it may be argued that changes in the activity of DA neurons in the midbrain DA nuclei are necessary to modulate cataplexy, while enhancement of DA transmission at the DA terminal in the mesolimbocortical and mesostriatal projections are important for the control of alertness (Nishino et al. 1998a). Because D2/D3 agonists are some of the most potent compounds in aggravating cataplexy (Nishino et al. 1991), and because the DA system is involved in both the regulation of alertness and cataplexy, we further characterized the effect of the most widely used D2/D3 antagonist, sulpiride (a benzamide neuroleptic), on cataplexy and sleep in our canine model.

In this study, we found that acute oral administration of sulpiride $(300,600 \mathrm{mg})$ significantly reduces cataplexy, consistent with the results of previous acute intravenous experiments of dopamine D2-type antagonists in the canine model (Nishino et al. 1991). We also found that acute administration of sulpiride did not significantly modify the amount of sleep. Interestingly, anticataplectic doses $(300 \mathrm{mg}$ ) of sulpiride did not significantly reduce REM sleep. This property contrasts with the effects of currently available anticataplectic compounds, such as tricyclic antidepressants or MAOIs (Scherschlicht et al. 1982). Indeed, anticataplectic doses of desipramine (0.4 $\mathrm{mg} / \mathrm{kg}$ i.v.), a tricyclic antidepressant currently used in the treatment of human narcolepsy, or nosoxetrine $(0.5$ $\mathrm{mg} / \mathrm{kg}$ i.v.), a selective adrenergic uptake inhibitor, almost completely reduce the amount of REM sleep in narcoleptic dogs evaluated under the same recording condition (Nishino et al. 1998a). The effect of sulpiride on REM sleep in narcoleptic dogs is also consistent with previous animal $(150 \mathrm{mg} / \mathrm{kg}$ p.o. in cats) and human (300-600 mg p.o. in humans) studies, which report no modification of REM sleep by sulpiride (Borenstein et 
al. 1969; Schneider et al. 1974, 1975). Sulpiride thus has a very unique profile: it is the first pharmacological compound found to discriminate the effect on cataplexy and REM sleep.

Sulpiride and other benzamides, such as amisulpiride, are commonly used in Europe and other countries as an antipsychotic, antidepressant and antidyspeptic drug (Wagstaff et al. 1994). The adverse effects of sulpiride include palpitation, sedation, extrapyramidal effects (acute dystonia or dyskinesia), galactorrhea and amenorrhea (Schoemaker et al. 1997). The compound is, however, well tolerated by subjects (Schoemaker et al. 1997). We therefore extended our studies to address the effect of chronic administration of sulpiride, to further evaluate the possible clinical application of sulpiride or other D2/D3 antagonists in human narcolepsy. Chronic oral administration of sulpiride significantly reduced cataplexy in canine narcolepsy. The tolerance observed was partial and cataplexy was well-controlled by adjusted dosing for all animals tested. We did not observe any behavioral changes such as sedation, or changes in hematology/blood chemistry after chronic drug administration. Chronic 2-week administration of sulpiride did not cause galactorrhea in the three male and three female dogs tested. Sulpiride is thus a promising anticataplectic compound that should be further studied in human narcolepsy.

Polygraphic data showed that chronic administration of sulpiride reduced wake and increased the duration of light and deep sleep in canines, a trend that has also been reported in humans (McClelland et al. 1990). However, consistent with the acute session, sulpiride did not significantly reduce REM sleep. The mean duration of episodes of drowsy, light sleep and deep sleep were, however, longer during chronic drug administration. Chronic administration of sulpiride thus tends to improve sleep fragmentation in narcoleptic dogs.

In the current study, we found that sulpiride antagonized the aggravation of cataplexy induced by $7-\mathrm{OH}-$ DPAT and quinpirole, two of the most selective and potent agonists for D2/D3 receptors (Levesque et al. 1992). It is demonstrated that behavioral effects of low doses of these compounds are mediated by D2/D3 autoreceptor stimulation (Daly and Waddington 1993) and that perfusion of a benzamide D2/D3 antagonist (raclopride) into the VTA and SN where D2/D3 cell body autoreceptors are enriched (Mercuri et al. 1997) reduces cataplexy (Reid et al. 1996), as do systemic administration of low doses of these compounds (Nishino et al. 1991). Taken together with the fact that sulpiride is relatively selective for D3 receptors (Sokoloff et al. 1990), the anticataplectic effect of sulpiride is likely to be mediated by blockade of D2/D3 autoreceptors. It is also known that systemic or local administration of D2/ D3 agonists into the VTA and SN significantly reduces the firing rate of dopaminergic neurons (Miller et al.
1983; Piercey et al. 1996; Trulson 1985). Because it is well demonstrated that dopamine neurons in the VTA and SN do not significantly reduce their firing during REM sleep, in contrast to noradrenergic neurons in the LC (Aston-Jones and Bloom 1981) and serotonergic neurons in the dorsal raphe (Trulson and Jacobs 1979), it may therefore be suggested that modulation of activity of the dopaminergic neurons in the midbrain and diencephalon is more specifically related to the regulation of cataplexy than REM sleep.

It was recently discovered that mutations in the gene for hypocretin receptor-2 (Hcrtr-2) induce narcolepsy in Dobermans and Labradors (Lin et al. 1999). Anatomical studies demonstrated that hypocretin neurons are exclusively located in the lateral hypothalamic area, but project to most brain structures, including the VTA and SN (Peyron et al. 1998); Hcrtr-2 are enriched in these dopaminergic nuclei (Lu, personal communication). Furthermore, it was also found that hypocretins excite some tyrosine hydroxylase-positive neurons isolated from the VTA in rats (Yada, personal communication). Thus, hypocretin-mediated disruption of excitatory inputs to the midbrain dopaminergic cell groups may be one of the major pathophysiologies in narcolepsy and thus may be responsible for the occurrence of EDS and cataplexy.

In the current study, we have demonstrated that sulpiride, a D2/D3 antagonist, significantly reduces cataplexy and improves sleep fragmentation, but has no effect on REM sleep in the canine model. Because recent results in canine narcolepsy suggest that fragmentation of sleep/wakefulness and cataplexy are two primary symptoms of narcolepsy, and that abnormalities in REM sleep regulation may be secondary, sulpiride may act on the system that is central to the pathophysiology of the disease. The differential effects on cataplexy and REM sleep by this compound may open a new avenue in developing a class of compounds that act more specifically on the abnormal symptoms of narcolepsy, with little effect on physiological sleep and sleep-related phenomena. Further pursuit of this line of investigation in narcoleptic research is warranted.

\section{ACKNOWLEDGMENTS}

The authors thank B. Ripley for editing the manuscript, and the staff of the Department of Comparative Medicine for technical assistance. This work is supported by NS 27710, NS23724, and MH01600.

\section{REFERENCES}

Akimoto H, Honda Y, Takahashi Y (1960): Pharmacotherapy in narcolepsy. Dis Nerv Sys 21:704-706

Aldrich MS (1992): Narcolepsy. Neurology 42:34-43 
Aston-Jones G, Bloom FE (1981): Activity of norepinephrinecontaining locus coeruleus neurons in behaving rats anticipates fluctuations in the sleep-waking cycle. J Neurosci 1:876-886

Baker TL, Dement WC (1985): Canine narcolepsy-cataplexy syndrome: evidence for an inherited monoaminergiccholinergic imbalance. In McGinty DJ, Drucker-Colin R, Morrison A, Parmeggiani PL (eds), Brain Mechanisms of Sleep. New York, Raven Press, pp 199-233

Baldessarini RJ (1983): How do antidepressants work? In Davis JM, Mass JW (eds), The Affective Disorders. Washington, DC, American Psychiatric Press, pp 243-260

Borenstein P, Champion C, Cujo P, Gekiere F, Olivenstein C, Kramarz P (1969): An original psychotropic drug: sulpiride. Sem Hop 45:1301-1314

Chemelli RM, Willie JT, Sinton CM, Elmquist JK, Scammell $\mathrm{T}$, Lee C, Richardson JA, Williams SC, Xiong $\mathrm{Y}$, Kisanuki Y, Fitch TE, Nakazato M, Hammer RE, Saper CB, Yanagisawa M (1999): Narcolepsy in orexin knockout mice: molecular genetics of sleep regulation. Cell 98:437-451

Daly SA, Waddington JL (1993): Behavioural effects of the putative D-3 dopamine receptor agonist 7-OH-DPAT in relation to other "D-2-like" agonists. Neuropharmacology 32:509-510

de Lecea L, Kilduff TS, Peyron C, Gao X, Foye PE, Danielson PE, Fukuhara C, Battenberg EL, Gautvik VT, Bartlett FS, Frankel WN, van den Pol AN, Bloom FE, Gautvik KM, Sutcliffe JG (1998): The hypocretins: hypothalamus-specific peptides with neuroexcitatory activity. Proc Natl Acad Sci USA 95:322-327

Diagnostic Classification Steering Committee, Thorpy MJ, Chairman (1990): ICSD—International Classification of Sleep Disorders: Diagnostic and Coding Manual. Rochester, Minnesota: American Sleep Disorders Association

Guilleminault C (1994): Narcolepsy syndrome. In Kryger MH, Roth T, Dement WC (eds), Principles and Practice of Sleep Medicine. Philadelphia, W.B. Saunders Company, pp 549-561

Guilleminault C, Wilson RA, Dement WC (1974): A study on cataplexy. Arch Neurol 31:255-261

Hagan JJ, Leslie RA, Patel S, Evans ML, Wattam TA, Holmes S, Benham CD, Taylor SG, Routledge C, Hemmati P, Munton RP, Ashmeade TE, Shah AS, Hatcher JP, Hatcher PD, Jones DN, Smith MI, Piper DC, Hunter AJ, Porter RA, Upton N (1999): Orexin A activates locus coeruleus cell firing and increases arousal in the rat. Proc Natl Acad Sci USA 96:10911-10916

Honda K, Riehl J, Mignot E, Nishino S (1999): Dopamine D3 agonists into the substratia nigra aggravates cataplexy but does not modify sleep. Neuroreport 10:3111-3118

Kaitin KI, Kilduff TS, Dement WC (1986): Sleep fragmentation in genetically narcoleptic dogs. Sleep 9:116-119

Levesque D, Diaz J, Pilon C, Martres MP, Giros B, Souil E, Schott D, Morgat JL, Schwartz JC, Sokoloff P (1992): Identification, characterization, and localization of the dopamine D3 receptor in rat brain using 7-[3H]hydroxy-N,N-di-npropyl-2- aminotetralin. Proc Natl Acad Sci USA 89:81558159

Lim RKS, Liu C-N, Moffitt RL (1960): A Stereotaxic Atlas of the Dog's Brain. Springfield, IL, Thomas Books
Lin L, Faraco J, Li R, Kadotani H, Rogers W, Lin X, Qiu X, de Jong PJ, Nishino S, Mignot E (1999): The sleep disorder canine narcolepsy is caused by a mutation in the hypocretin (orexin) receptor 2 gene [see comments]. Cell 98:365-376

McClelland GR, Cooper SM, Pilgrim AJ (1990): A comparison of the central nervous system effects of haloperidol, chlorpromazine and sulpiride in normal volunteers. Br J Clin Pharmacol 30:795-803

Mercuri NB, Saiardi A, Bonci A, Picetti R, Calabresi P, Bernardi G, Borrelli E (1997): Loss of autoreceptor function in dopaminergic neurons from dopamine D2 receptor deficient mice. Neuroscience 79:323-327

Mignot E, Guilleminault C, Bowersox S, Fruhstorfer B, Nishino S, Maddaluno J, Ciaranello R, Dement WC (1989): Central alpha-1 adrenoceptor subtypes in narcolepsy-cataplexy: a disorder of REM sleep. Brain Res 490: 186-191

Mignot E, Renaud A, Nishino S, Arrigoni J, Guilleminault C, Dement WC (1993): Canine cataplexy is preferentially controlled by adrenergic mechanisms: evidence using monoamine selective uptake inhibitors and release enhancers. Psychopharmacology 113:76-82

Miller JD, Farber J, Gatz P, Roffwarg H, German DC (1983): Activity of mesencephalic dopamine and non-dopamine neurons across stages of sleep and waking in the rat. Brain Res 273:133-141

Mitler MM, Dement WC (1977): Sleep studies on canine narcolepsy: pattern and cycle comparisons between affected and normal dogs. Electroencephalogr Clin Neurophysiol 43:691-699

Nishino S, Arrigoni J, Shelton J, Dement WC, Mignot E (1993a): Desmethyl metabolites of serotonergic uptake inhibitors are more potent for suppressing canine cataplexy than their parent compounds. Sleep 16:706-712

Nishino S, Arrigoni J, Valtier D, Miller JD, Guilleminault C, Dement WC, Mignot E (1991): Dopamine D2 mechanisms in canine narcolepsy. J Neurosci 11:2666-2671

Nishino S, Fruhstorfer B, Arrigoni J, Guilleminault C, Dement WC, Mignot E (1993b): Further characterization of the alpha-1 receptor subtype involved in the control of cataplexy in canine narcolepsy. J Pharmacol Exp Ther 264:1079-1084

Nishino S, Haak L, Shepherd H, Guilleminault C, Sakai T, Dement WC, Mignot E (1990): Effects of central alpha-2 adrenergic compounds on canine narcolepsy, a disorder of rapid eye movement sleep. J Pharmacol Exp Ther 253:1145-1152

Nishino S, Honda K, Riehl J, Mignot E (2000a): Extracellular single unit recordings of dopaminergic neurons in the ventral tegmental area in narcoleptic dobermans. Sleep 23S2:A1 (APSS abstract)

Nishino S, Mao J, Sampathkumaran R, Shelton J, Mignot E (1998a): Increased dopaminergic transmission mediates the wake-promoting effects of CNS stimulants. Sleep Research Online 1:49-61

Nishino S, Mignot E (1997): Pharmacological aspects of human and canine narcolepsy. Prog Neurobiol 52:27-78

Nishino S, Riehl J, Hong J, Kwan M, Honda K, Mignot E (1999): REM sleep, but not cataplexy, is controlled by a 30-minute normal ultradian rhythm in narcoleptic canines. Sleep 22S:S2 (APSS abstract) 
Nishino S, Riehl J, Mignot E (1998b): Effects of dopaminergic and noradrenergic uptake inhibitors on dopaminergic D3 agonist-included cataplexy. Sleep 21S:S181 (APSS abstract)

Nishino S, Ripley B, Overeem S, Lammers GJ, Mignot E (2000b): Hypocretin (orexin) deficiency in human narcolepsy. Lancet 355:39-40

Nishino S, Tafti M, Reid MS, Shelton J, Siegel JM, Dement WC, Mignot E (1995): Muscle atonia is triggered by cholinergic stimulation of the basal forebrain: implication for the pathophysiology of canine narcolepsy. J Neurosci 15:4806-4814

Nissbrandt N, Engberg G, Pileblad E (1991): The effects of GBR 12909, a dopamine re-uptake inhibitor, on monoaminergic neurotransmission in rat striatum, limbic forebrain, cortical hemispheres and substantia nigra. Naunyn-Schmiedeberg's Arch Pharmacol 344:16-28

Okura M, Honda K, Riehl J, Mignot E, Nishino S (1999): Roles of diencephalic dopaminergic cell groups in regulation of cataplexy in canine narcolepsy. Sleep 22S:S1 (APSS abstract)

Peyron C, Tighe DK, van den Pol AN, de Lecea L, Heller HC, Sutcliffe JG, Kilduff TS (1998): Neurons containing hypocretin (orexin) project to multiple neuronal systems. J Neurosci 18:9996-10015

Piercey MF, Hoffmann WE, Smith MW, Hyslop DK (1996): Inhibition of dopamine neuron firing by pramipexole, a dopamine D3 receptor-preferring agonist: comparison to other dopamine receptor agonists. Eur J Pharmacol 312:35-44

Reid MS, Nishino S, Tafti M, Siegel JM, Dement WC, Mignot E (1998): Neuropharmacological characterization of basal forebrain cholinergic stimulated cataplexy in narcoleptic canines. Exp Neurol 151:89-104

Reid MS, Tafti M, Nishino S, Sampathkumaran R, Siegel JM, Dement WC, Mignot E (1996): Local administration of dopaminergic drugs into the ventral tegmental area modulate cataplexy in the narcoleptic canine. Brain Res 733:83-100

Roth B, Bruhova S, Lehovsky M (1969): REM sleep and NREM sleep in narcolepsy and hypersomnia. Electroenceph Clin Neurophysiol 26:176-182

Scherschlicht R, Polc P, Schneeberger J, Steiner M, Haefely W (1982): Selective supression of rapid eye movement sleep (REMS) in cats by typical and atypical antidepressants. Adv Biochem Psychopharmacol 31:359-364

Schneider E, Ziegler B, Maxion H, Badawi M (1974): Longand short-term effects of sulpiride on sleep-EEG of man. Arzneimittelforschung 24:990-993
Schneider E, Ziegler B, Maxion H, Badawi M (1975): The influence of sulpirid on sleep. Results of polygraphic night sleep recordings. Pharmakopsychiatr Neuropsychopharmakol 8:90-98

Schoemaker H, Claustre Y, Fage D, Rouquier L, Chergui K, Curet O, Oblin A, Gonon F, Carter C, Benavides J, Scatton B (1997): Neurochemical characteristics of amisulpride, an atypical dopamine D2/D3 receptor antagonist with both presynaptic and limbic selectivity. J Pharmacol Exp Ther 280:83-97

Schrader H, Bendixen-Markset AC, Treidene HE (1986): The treatment of accessory symptoms in narcolepsy: a double-blind cross-over study of a selective serotonin reuptake inhibitor (femoxetine) versus placebo. Acta Neurol Scand 74:297-303

Siegel JM, Nienhuis R, Fahringer H, Paul R, Shiromani P, Dement WC, Mignot E, Chiu C (1991): Neuronal activity in narcolepsy: identification of cataplexy related cells in the medial medulla. Science 262:1315-1318

Siegel JM, Nienhuis R, Fahringer HM, Chiu C, Dement WC, Mignot E, Lufkin R (1992): Activity of medial mesopontine units during cataplexy and sleep-waking states in the narcoleptic dog. J Neurosci 13:1640-1646

Sokoloff P, Giros B, Martres MP, Bouthenet ML, Schwartz IC (1990): Molecular cloning and characterization of a novel dopamine receptor (D3) as a target for neuroleptics. Nature 347:146-151

Takahashi Y (1971): Narcoleptic syndrome and paradoxical sleep. Saishin-Igatu 26:98-105

Thorpy MJ, Goswami M (1990): Treatment of narcolepsy. In Thorpy MJ (ed), Handbook of Sleep Disorders. New York, Marcel Dekker, Inc., pp 235-258

Trulson ME (1985): Activity of dopamine-containing substantia nigra neurons in freely moving cats. Neurosci Biobehav Rev 9:283-297

Trulson ME, Jacobs BL (1979): Raphe unit activity in freely moving cats: correlation with level of behavioral arousal. Brain Res 163:135-150

Wagstaff A, Fitton A, Benfield P (1994): Sulpiride; a review of its pharmacodynamic and pharmacokinetic properties, and therapeutic efficacy in schizophrenia. CNS Drugs 2:313-333

Wu MF, Gulyani SA, Yau E, Mignot E, Phan B, Siegel JM (1999): Locus coeruleus neurons: cessation of activity during cataplexy. Neuroscience 91:1389-1399 